\title{
Los incentivos económicos se asocian a cesación tabáquica a corto plazo en adultos jóvenes, pero no todas sus modalidades son igualmente aceptadas
}

Financial incentives are associated to short term smoking cessation in young adults, but not all modalities are similarly accepted

Halpern SD, y col. N Engl J Med 2015:372(22):2108-17

\section{Objetivos}

Evaluar la efectividad y aceptabilidad de cuatro modalidades de incentivos económicos destinados a aumentar la tasa de cesación tabáquica a seis meses, comparadas entre si y contra el cuidado habitual.

\section{Diseño, lugar y pacientes}

Estudio aleatorizado controlado, estratificado por cobertura médica e ingreso económico. Incluyó a 2.538 empleados de una cadena nacional de farmacias en EE.UU. o a sus familiares y amigos. Los participantes debían ser mayores de 18 años y fumadores de al menos cinco cigarrillos diarios. Además debían estar interesados en dejar de fumar en el transcurso de los 90 días próximos al enrolamiento y disponer de acceso a internet. El reclutamiento se realizó a través de comunicación interna.

\section{Intervenciones}

Todos los participantes recibieron información sobre los servicios disponibles de cesación y material impreso. Los pacientes fueron aleatorizados a cinco grupos: a) Recompensa individual acumulativa de hasta USD 800; b) Recompensa grupal colaborativa (mayor recompensa cuanto más miembros de un grupo de seis personas permanecían abstinentes); c) Reintegro de depósito inicial individual (USD 150) y recompensa de USD 650; d) Reintegro de un depósito inicial y recompensa acumulativa según el número de abstinentes de un grupo; y e) Cuidado habitual (no recibían incentivos económicos).Para los primeros cuatro grupos, los incentivos se otorgaban contra comprobación de abstinencia durante los primeros seis meses.

\section{Medición de resultados principales}

Abstinencia sostenida determinada bioquímicamente con cotinina o anabasina a seis meses (objetivo primario) y a 12 meses (objetivo secundario). El análisis se realizó por intención de tratar.

\section{Resultados principales}

La mediana de edad de la población se hallaba en la tercera década de vida, con predominio femenino ( $>60 \%)$, y contaban con educación secundaria completa. Fumaban en promedio 15 cigarrillos al día, con nivel de dependencia nicotínica bajo a moderado en cerca de la mitad de los casos. El $41 \%$ de los participantes tenía, por cobertura laboral, reemplazo nicotínico gratuito y apoyo conductual.

La abstinencia continua a seis meses fue mayor para los grupos asignados a incentivos (rango 9,4 a 16\%) respecto al comparador $(6,0 \% ; p<0,05)$. A los 12 meses, los resultados fueron superiores en las ramas de recompensa (ver tabla 1 ).

A seis meses, los programas individuales no mostraron diferencias en la tasa de cesación respecto de los grupales (13,7 vs. $12,1 \% ; p=0,29)$. Los programas con recompensa se asociaron a mayor tasa de abstinencia que los de reintegro (15,7 vs. $10,2 \% ; p<0,001)$. El $90 \%$ de los participantes asignados a recompensa (individual o grupal) manifestaron aceptar su asignación comparado contra el $13,7 \%$ de los asignados a depósito y reintegro $(p<0,001)$. Entre quienes afirmaron aceptar cualquier intervención, la abstinencia fue 13 puntos mayor a favor de los programas de reintegro.

Tabla 1: porcentajes de abstinencia a 6 y 12 meses según grupo.

\begin{tabular}{|c|c|c|c|c|c}
\multicolumn{1}{c|}{ Resultado } & $\begin{array}{c}\text { Cuidado habitual } \\
\text { (comparador) } \\
\mathbf{n = 4 6 8}\end{array}$ & $\begin{array}{c}\text { Recompensa } \\
\text { individual } \\
\mathbf{n = 4 6 8}\end{array}$ & $\begin{array}{c}\text { Recompensa } \\
\text { grupal } \\
\mathbf{n = 5 1 9}\end{array}$ & $\begin{array}{c}\text { Reintegro } \\
\text { individual } \\
\mathbf{n = 5 8 2}\end{array}$ & $\begin{array}{c}\text { Reintegro } \\
\text { grupal } \\
\mathbf{n}=\mathbf{4 7 1}\end{array}$ \\
\hline Abstinencia a seis meses* \% (IC 95\%) & $6(3,9 \mathrm{a} 8,2)$ & $15,4(12,2 \mathrm{a} 18,5)$ & $16(12,9 \mathrm{a} 19,2)$ & $9,4(7,1 \mathrm{a} 11,8)$ & $11,1(8,3 \mathrm{a} 14)$ \\
\hline Abstinencia a doce meses*\% (IC 95\%) & $3,4(1,8 \mathrm{a} 5,1)$ & $7,5(5,2 \mathrm{a} 9,8)$ & $8,7(6,3 \mathrm{a} 11,2)$ & $3,5(2 \mathrm{a} 5)$ & $6,2(4 \mathrm{a} 8,4)$ \\
\hline
\end{tabular}

*Ajustadas por cobertura médica e ingreso económico. IC 95\%: intervalo de confianza del 95\%.

\section{Conclusiones}

Los programas basados en recompensas fueron más aceptados que los basados en reintegros, y produjeron mayores tasas de cesación. Los programas grupales e individuales presentan resultados similares.

Fuente de financiamiento: National Institutes of Health y CVS Caremark (cadena farmacéutica).

\section{¡Vos también podes formar parte de esta transformación!}

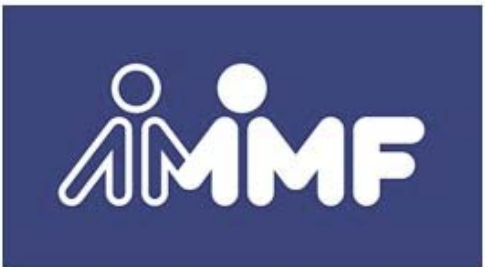

Asociación Metropolitana de Medicina Familiar.

Si queres asociarte o que te brindemos mayor información: secretaria.ammf@gmail.com

Seguinos en Facebook: www.facebook.com/AsociacionMetropolitanadeMedicinaFamiliar 


\section{Comentario}

Distintos estudios muestran que los incentivos económicos promueven comportamientos saludables en distintos contextos, incluyendo la cesación tabáquica ${ }^{1,2}$. Su eficacia se asumía como vinculada al monto, pero distintas modalidades (recompensa contra reintegro), a igual monto, pueden tener distinta eficacia según la aversión al riesgo de las personas.

Este estudio, realizado en personas en edad productiva, trabajadores de una empresa de salud, o sus familiares y amigos, encontró que los programas de incentivos individuales o grupales se asociaron a mayores tasas de cesación que el comparador. Se encontró además que la modalidad de reintegro, en la cual el participante toma un riesgo, era menos aceptada que la modalidad de recompensa, y que entre los que aceptaban ambas modalidades, el reintegro se asociaba a mayor tasa de abstinencia, lo que podría atribuirse al efecto de la autoconfianza. El estudio presenta algunas limitaciones. La selección de personas jóvenes, con trabajo e interesadas en dejar de fumar, podría limitar su generalización, en particular para fumadores con mayor carga tabáquica o mayor adicción. Además los autores modificaron la asignación por protocolo por las grandes diferencias de aceptabilidad. La presencia de cobertura de tratamiento gratuito en el $41 \%$ de los participantes podría modificar el tamaño del efecto en otros escenarios. Por último, no hubo constatación biológica de cesación en el 50\% de los abstinentes a 12 meses, lo cual disminuye la precisión de la estimación de efectividad para este resultado ${ }^{3}$.

\section{Conclusiones del comentador}

Los programas de incentivos económicos grupales o individuales para dejar de fumar, en el contexto de una empresa y dirigidos a empleados jóvenes, pueden ser útiles para aumentar las tasas de cesación a seis meses, siendo su eficacia menor hacia el año. Los programas basados en recompensas son más aceptados que los basados en reintegros, pero en quienes aceptan ambas modalidades, los programas de reintegros podrían resultar más efectivos. Estos programas pueden tener distinta efectividad en distintos contextos socioculturales, ya que requieren de apoyo terapéutico independiente a la cesación y de una población educada y con disponibilidad de recursos.

Alejandro J. Videla [ Clínica de Tabaquismo del Hospital Universitario Austral, Dirección de Promoción de la Salud y Control de Enfermedades No Transmisibles del Ministerio de Salud de la Nación Argentina, avidela@cas.austral.edu.ar ]

Videla AJ. Los incentivos económicos se asocian a cesación tabáquica a corto plazo en adultos jóvenes, pero no todas sus modalidades son igualmente aceptadas. Evid Act Pract Ambul 2016;19(4):107-108. Comentado de: Halpern SD, y col. Randomized trial of four financial-incentive programs for smoking cessation. NEJM. 2015;372(22):2108-17. PMID: 25970009.

\section{Referencia}

1. Giles EL, y col. The Effectiveness of Financial Incentives for Health Behaviour Change: Systematic Review and Meta-Analysis. PLoS ONE. 2014;9(3):e90347. PubMed PMID: PMC3949711.

2. Cahill K, y col. Incentives for smoking cessation. The Cochrane database of systematic reviews. 2015;5:CD004307. PubMed PMID: 25983287.

3. West R, y col. Outcome criteria in smoking cessation trials: proposal for a common standard. Addiction. 2005;100(3):299-303.

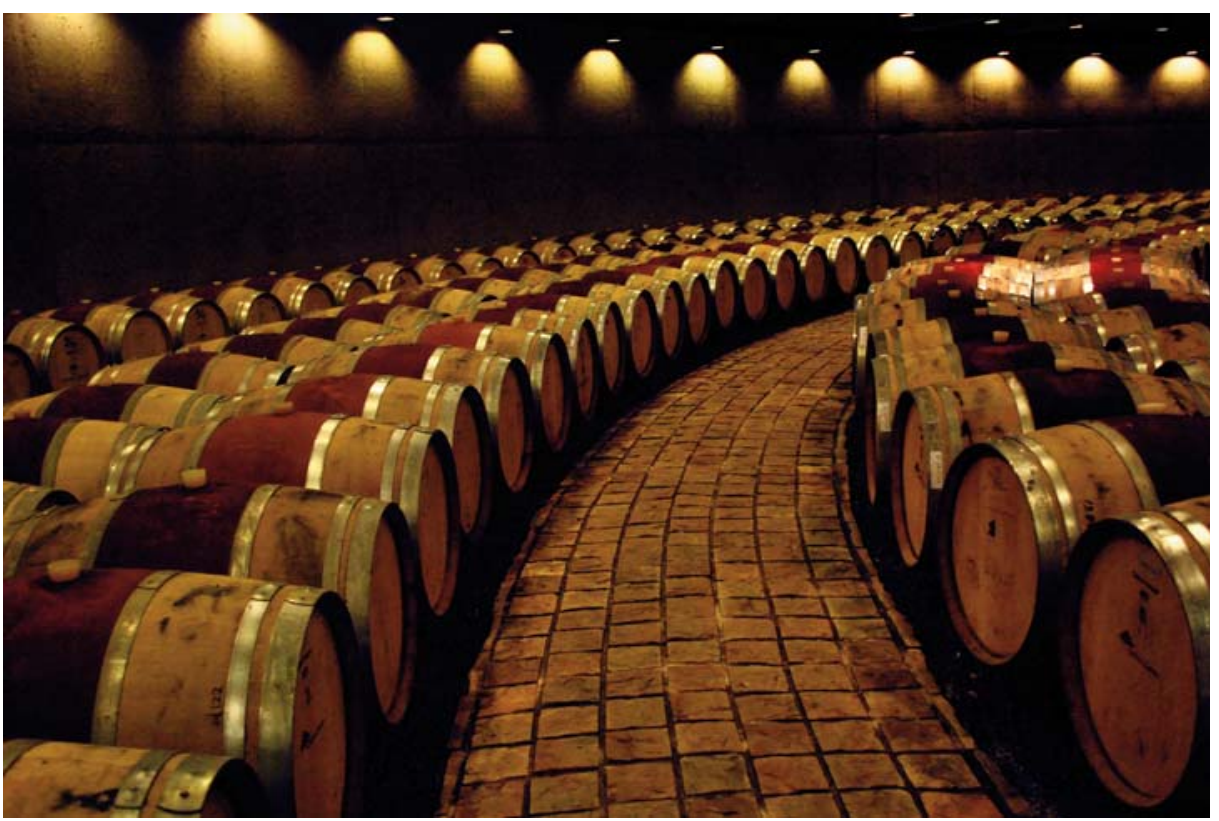

Cortesía: Silvia Spina 